Original Research Paper

\title{
Fracture Initiation at the Zirconia/Veneer Interface-A Finite Element Simulation
}

\author{
${ }^{1}$ Mirsayar, M.M. and ${ }^{2}$ A.T. Samaei \\ ${ }^{1}$ Department of Civil Engineering, Texas A\&M University, College Station, TX 77843-3136, USA \\ ${ }^{2}$ School of Engineering, University of California Merced, Merced, California 95343, USA
}

Article history

Received: 29-04-2015

Revised: $29-05-2015$

Accepted: 30-05-2015

Corresponding Author:

Mirsayar, M.M.

Department of Civil Engineeing,

Texas A\&M University, College

Station, TX 77843-3136, USA

Email:mirmilad@tamu.edu

\begin{abstract}
Zirconia/veneer bilayered components are extensively used in dental restoration technology to improve resistance of tooth's surface from decay. The direction of the fracture propagation at the interface of zirconia and veneer is investigated in this study. Finite element analysis is performed on a bi-material four point bend specimen in different geometries and the fracture initiation angle is obtained using Maximum Tangential Stress (MTS) criterion. The effect of specimen geometry on the fracture initiation angle is discussed. Because an interface crack may propagate through interface or kink into one of the materials, some comments are given to determine under which condition "interface debonding" will be happened.
\end{abstract}

Keywords: Interface Crack, Zirconia, Veneer, Fracture Initiation, Finite Element

\section{Introduction}

Restored teeth undergo complex loading conditions during their service life (Chai et al., 2014; Kosyfaki and Swain, 2014; Kotousov et al., 2011). Veneers which are made from dental porcelain or composite, are widely used in dentistry to protect tooth's surface from decay. In dental prostheses, the zirconia-based bi-material restorations are widely employed to reform the damaged parts of teeth. That is because the veneering porcelain sintered on zirconia (zirconia/veneer interface) has a high strength (Mosharraf et al., 2011; Gostemeyer et al., 2010; Fischer et al., 2008; Kim et al., 2011).

In a restored tooth, under service condition, cracks may develop at the interface of zirconia and veneer as a result of the external mechanical loading. Thus, the study of fracture propagation condition at the interface of the zirconia and veneer is an important issue in the field of dentistry. Generally, the interfacial fracture has widely been investigated by many researchers so far (Arabi et al., 2013; Ayatollahi et al., 2010a; 2010b; 2011; Ayatollahi and Mirsayar, 2011; Mirsayar, 2013; 2014a; 2014b; Mirsayar and Samaei, 2013; 2014; Mirsayar et al. 2014). Previously, the researchers have mostly focused on the enhancement of the bond strength rather than fracture mechanics aspect of the zirconia/ veneer interfaces (Mosharraf et al., 2011; Kim et al., 2011). However, in the past few years, researchers were interested in interfacial fracture resistance of the allceramic restorations (Kotousov et al., 2011; Gostemeyer et al., 2012). Several fracture test specimens are employed by the researchers in the past to investigate the interfacial fracture resistance of the specimens containing a bi-material and simple cracks (Ayatollahi et al., 2013; Charalambides et al., 1989; Yuuki and Xu, 1992; Mirsayar, 2014c; 2015). Among them, the bi-material four point bend specimen developed by Charalambides et al. (1989) has widely been accepted by the researchers. They have conducted experiments on the bi-material four point bend specimens made from Aluminum and PMMA.

There are several fracture criteria to investigate the fracture initiation conditions at the interfacial crack tip. The well-known fracture criteria are: The Maximum Tangential Stress (MTS) (Yuuki and Xu, 1992), $\mathrm{K}_{\mathrm{II}}=0$ (Cotterell and Rice, 1980) and energy release rate $(G)$ (He and Hutchinson, 1989). However, these criteria are modified recently to provide more accurate estimation of the test results depending on different specimen geometries and boundary conditions. For instance, Mirsayar (2014a) showed that to achieve an accurate estimation of the interfacial fracture resistance, the first non-singular stress term of the elastic stress field (called T-stress) should also be considered when employing MTS criterion. 
In this study, the fracture initiation condition at the interface of the zirconia and veneer is studied using bimaterial four point bend specimen suggested by Charalambides et al., (1989). The finite element software ABAQUS is employed to simulate the specimen in different geometries. For each case, the direction of the fracture initiation is obtained using MTS criterion. Finally, some comments are given about the possibility of the crack kinking out of the interface as well as crack propagation through the interface.

\section{Problem Statement}

Figure 1 shows the general configuration of the bimaterial four point bend specimen made from zirconia and veneer. The specimen has a central notch through the thickness of the veneer (top layer) which meets the middle of the symmetrical interface crack. The specimen is simulated in different thickness layer ratio $\left(h_{1} / h_{2}=\right.$ $0.5,1,2)$ and different normalized crack sizes $(\mathrm{a} / \mathrm{c}=0.1$, 0.3 ). The elastic properties of the veneer (IPS e.max Ceram) and zirconia (Lava Zirconia) are $E_{v}=70 \mathrm{GPa}, v_{v}$ $=0.27$ and $E_{z}=210 \mathrm{GPa}, v_{z}=0.31$, respectively, where $E_{i}$ is the elastic modulus and $v_{i}$ is the Poison's ratio of each material ( $\mathrm{i} \equiv \mathrm{v}, \mathrm{z}$ ) (Wang et al., 2014).

When the specimen is loaded, the interfacial crack may propagate through the interface or may kink into one of the materials depending on the strength of the interface. Based on the experimental observation given in literature (see for instance, Wang et al., 2014) the zirconia/ veneer bonded joints can be considered as "strong interfaces" and hence, the interface crack usually kinks into one of the materials instead of growing through the interface. However, the mechanism of the crack propagation at the interface is affected by the strength of the interface as well as each material.

\section{Results and Discussion}

\section{Finite Element Simulation of the Specimen}

Figure 2 shows a typical finite element mesh generated using eight node plane strain elements along with an expanded view of the crack tip singular elements (for $h_{1} / h_{2}=1$ and $\mathrm{a} / \mathrm{c}=0.1$ ). The specimen is simulated in different geometries to obtain the effect of geometry on the crack initiation condition at the interface crack tip.

\section{MTS Criterion for Initiation at the Crack Tip}

Based on the MTS criterion, for brittle materials, the crack propagates at the critical distance of $r_{c}$ from the crack tip in direction where the tangential stress, $\sigma_{\theta \theta}$, reaches its ultimate strength. This criterion was developed originally for problem of a crack which exists in a homogeneous media. However, by the same concept, the MTS criterion could be applied for the interface cracks by controlling the ultimate strength of both materials (at their corresponding critical distances, $r_{c}^{(i)}$ ) as well as the strength of the interface. For "strong interfaces", the MTS criterion could be expressed as follows Equation 1:

$\left\{\begin{array}{l}\left(\frac{\partial \sigma_{\theta \theta}^{(i)}}{\partial \theta}\right)_{r_{c}^{(i)}, \theta_{0}^{(i)}}=0 \\ \left(\frac{\partial^{2} \sigma_{\theta \theta}^{(i)}}{\partial \theta^{2}}\right)_{r_{c}^{(i)}, \theta_{0}^{(i)}}<0\end{array}\right.$

where, the critical distance, $r_{c}^{(m)}$, is defined as Equation 2:

$r_{c}^{(i)}=\frac{1}{2 \pi}\left(\frac{K_{I C}^{(i)}}{\sigma_{C}^{(i)}}\right)^{2}$

where, $K_{I C}^{(i)}$ and $\sigma_{C}^{(i)}$ are fracture toughness and ultimate tensile stress of each material, respectively. The elastic tangential stress field, $\sigma_{\theta \theta}$, is expressed in form of a series of expansion with infinite terms containing singular (first and second terms) and nonsingular terms, as follows Equation 3:

$\sigma_{\theta \theta}^{(i)}=\frac{K_{1}}{\sqrt{2 \pi r}} f_{\theta \theta, 1}^{(i)}+\frac{K_{2}}{\sqrt{2 \pi r}} f_{\theta \theta, 2}^{(i)}+T^{(i)}+($ H.O.T $)$

where, $K_{1}$ and $K_{2}$ are the stress intensity factors corresponding to opening and sliding mode, respectively. The parameter $\mathrm{T}$, called T-stress, corresponds to the first non-singular stress term (more details can be found in Mirsayar, 2014a). Although, in vicinity of the crack tip, the singular terms can reasonably predict the tangential stress field, it is recently shown by Mirsayar (2014a) that the first non-singular term sometimes plays an important role in prediction of the tangential stress distribution as well as the fracture initiation conditions around the crack tip. However, in this paper, the fracture initiation direction is predicted by the tangential stress which is directly obtained through finite element analysis.

\section{Finite Element Results}

Figure 3 shows the distribution of the normalized tangential stress in different angles, $\theta$, in two normalized crack lengths, $\mathrm{a} / \mathrm{c}=0.1$ and 0.3 . All curves are plotted at the radial distance of $r=0.2 \mathrm{~mm}$ which is within the regular range of the critical distances reported for ceramic materials (Aliha and Ayatollahi, 2012). It is seen that normalized tangential stress increases by increasing $h_{1} / h_{2}$ ratio. That means by increasing the thickness of the veneer (top layer) and decreasing the thickness of the zirconia, the tangential stress at the interfacial crack tip is increased and as a results, the fracture load is decreased. 


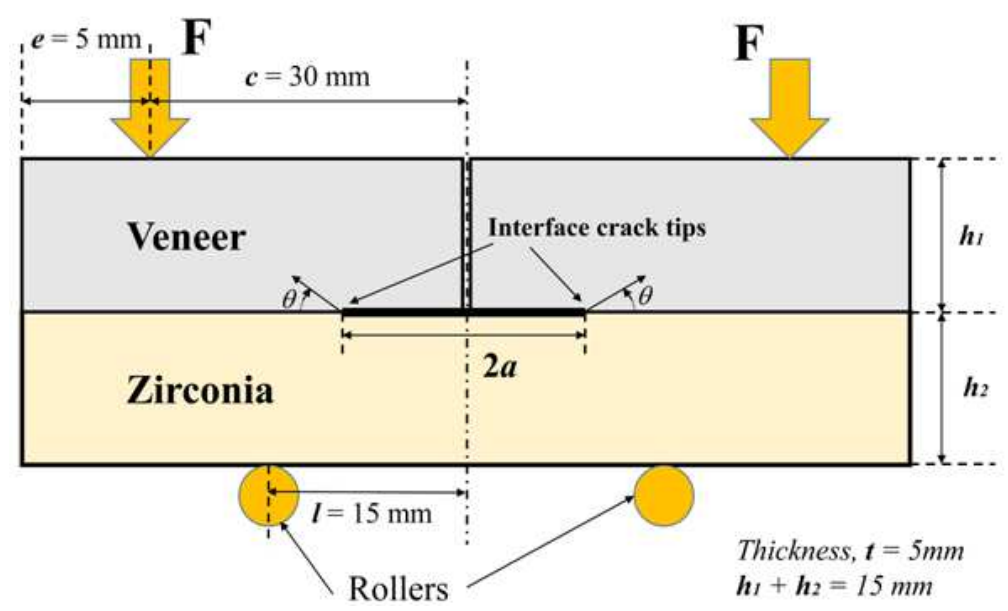

Fig. 1. General configuration of the bi-material four point bend specimen

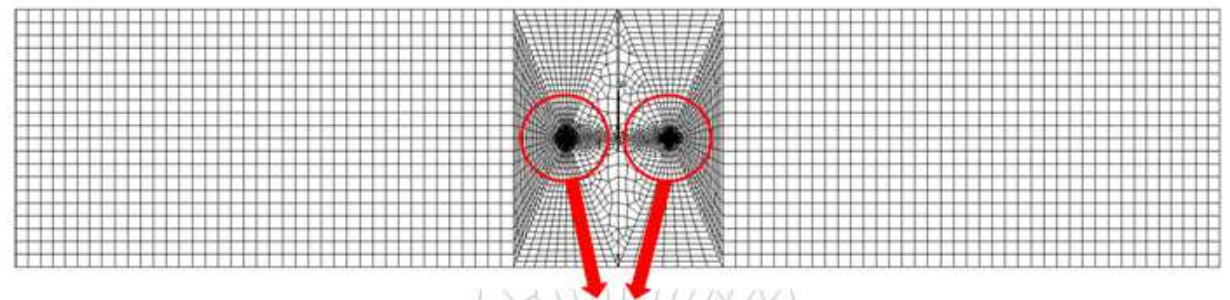

Fig. 2. Typical finite element mesh pattern of the bi-material four point bend specimen

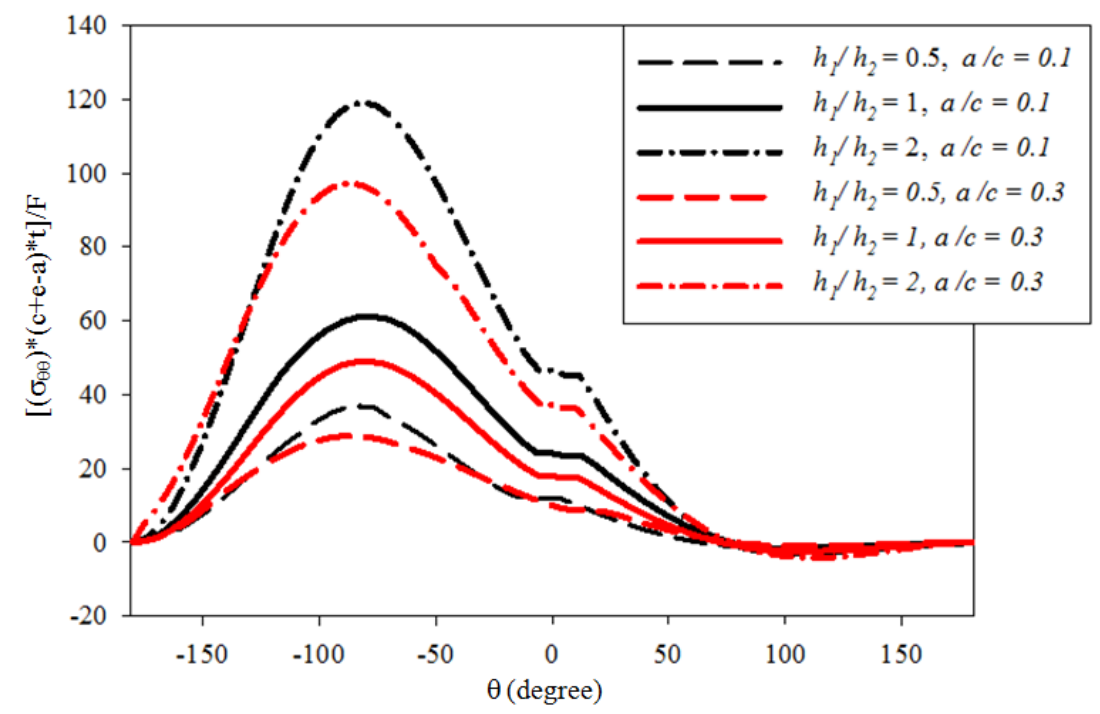

Fig. 3. Distribution of the normalized tangential stress versus tangential direction at $r=r_{c}=0.2 \mathrm{~mm}$ 


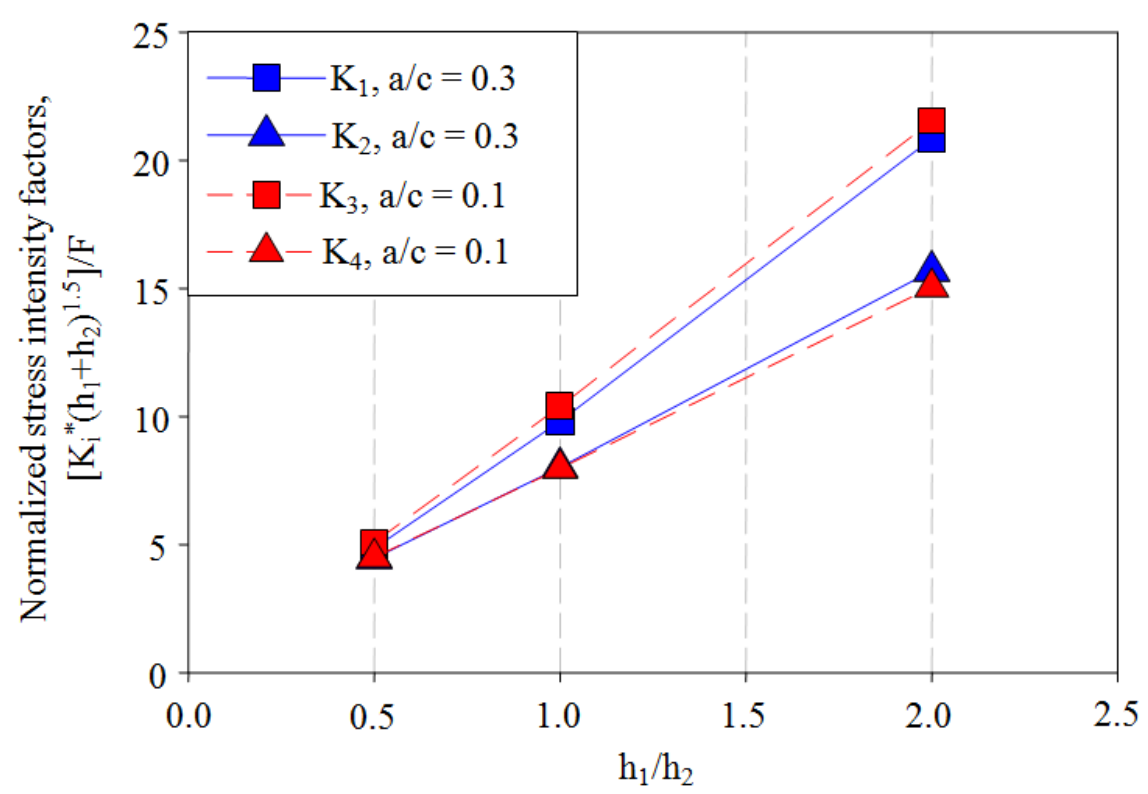

Fig. 4. Variation of the normalized stress intensity factors versus $h_{1} / h_{2}$ ratio

According to Figure 3, the tangential stress reaches its maximum value in zirconia part of the specimen. However, depending on the strength of the interface, crack may kink into the zirconia part or propagate through the interface. It should be noted that regardless of the stiffness of the veneer part, the crack will never kink into the zirconia part because the tangential stress at the veneer part reaches its maximum value at the interface. It also could be seen from Fig. 3 that the ratio of $\sigma_{z, \max } / \sigma_{\text {int }}$ is decreased by the increasing $h_{1} / h_{2}$ ratio ( $\sigma_{z, \max }$ and $\sigma_{\text {int }}$ are the maximum value of the normalized tangential stress in zirconia part and at the interface, respectively). That means by increasing the $h_{1} / h_{2}$ ratio, the possibility of crack propagation through the interface is decreased by increasing $h_{1} / h_{2}$ ratio. In other words, the simulation results show that, for $\mathrm{a} / \mathrm{c}=$ 0.1 and 0.3 , the interface strength (under pure tension) must be at least 2.5 times weaker than tensile strength of the zirconia for having "interface debonding" (crack propagation through the interface). Also the comparison between results for $\mathrm{a} / \mathrm{c}=0.1$ and $\mathrm{a} / \mathrm{c}=0.3$ shows that the possibility of the interface debonding slightly decreases by increasing the crack length (assuming the same interface strength).

Assuming a strong interface in which the crack kinks into the zirconia part, the fracture initiation angle (with respect to the interface) in zirconia part slightly decreases by increasing $h_{1} / h_{2}$ ratio from $-78^{\circ}$ to $-82^{\circ}$ and from $-80^{\circ}$ to $-86^{\circ}$ for $\mathrm{a} / \mathrm{c}=0.1$ and 0.3 , respectively. That means the fracture propagation angle in zirconia part slightly increases by increasing the crack length. It is also observed from Fig. 3 that distribution of the tangential stress field in veneer part approaches zero for $\theta>80^{\circ}$. That happens because of the central notch through the thickness of the veneer which provides a stress free area at the veneer part for small values of $\mathrm{a} / \mathrm{c}$ ratio.

The variation of the normalized stress intensity factors versus the $h_{1} / h_{2}$ ratio and for both normalized crack lengths is illustrated in Fig. 4.

It is shown that the both opening and sliding mode of the fracture are increased by increasing the $h_{1} / h_{2}$ ratio. However, the opening and sliding stress intensity factors slightly decrease and increase by increasing the normalized crack length, respectively. That means by increasing the normalized crack length, the role of shear stress in the crack initiation condition becomes more important and conversely, the role of normal stresses becomes less important.

\section{Conclusion}

The bi-material four point bend specimen, made from zirconia and veneer, is simulated in this paper in different geometries by means of finite element method. The fracture initiation direction is obtained for each cases and the geometry effects are discussed. The condition in which a crack propagates through the interface or kinks into one of the materials is highlighted. Although, the bi-material four point bend specimen is a well-known fracture test specimen, no recommendation is currently given in literature for using this specimen for zirconia/veneer interface which are widely used in dental materials. Therefore, the results of this paper could be useful in standardization of the zirconia/veneer fracture tests. 


\section{Funding Information}

The authors have no support or funding to report.

\section{Author's Contributions}

Mirsayar, M.M.: Conception and design, data acquisition, Framework.

A.T. Samaei: Drafting article.

\section{Ethics}

This article is original and contains unpublished material. The corresponding author confirms that all of the other authors have read and approved the manuscript and no ethical issues involved.

\section{References}

Aliha, M.R.M. and M.R. Ayatollahi, 2012. Analysis of fracture initiation angle in some cracked ceramics using the generalized maximum tangential stress criterion. Int. J. Solids Structures, 49: 1877-1883. DOI: 10.1016/j.ijsolstr.2012.03.029

Arabi, H., M.M. Mirsayar, A.T. Samaei and M. Darandeh, 2013. Study of characteristic equation of the elastic stress field near bimaterial notches. Strength Mater., 45: 598-606. DOI: $10.1007 /$ s1 1223-013-9497-3

Ayatollahi, M.R., M. Dehghany and M.M. Mirsayar, 2013. A comprehensive photoelastic study for mode I sharp V-notches. Eur. J. Mechan. A/Solids, 37: 216-230. DOI: 10.1016/j.euromechsol.2012.07.001

Ayatollahi, M.R. and M.M. Mirsayar, 2011. Kinking angles for interface cracks. Proc. Eng., 10: 325-329. DOI: $10.1016 /$ j.proeng.2011.04.056

Ayatollahi, M.R., M.M. Mirsayar and M. Dehghany, 2011. Experimental determination of stress field parameters in bi-material notches using photoelasticity. Mater. Design, 32: 4901-8. DOI: 10.1016/j.matdes.2011.06.002

Ayatollahi, M.R., M.M. Mirsayar and M. Nejati, 2010a. Evaluation of first non-singular stress term in bi material notches. Comput. Mater. Sci., 50: 752-60. DOI: 10.1016/j.commatsci.2010.10.007

Ayatollahi, M.R., M. Nejati and M.M. Mirsayar, 2010b. An overdeterministic method for stress analysis of bi material corners and interface cracks using finite element method. Proceedings of the 9th Conference of Iranian Aerospace Society, (IAS' 10), Tehran, Iran.

Chai, H., J.J.W. Lee, A.J. Mieleszko, S.J. Chu and Y. Zhang, 2014. On the interfacial fracture of porcelain/zirconia and graded zirconia dental structures. Acta Biomaterialia, 10: 3756-3761.

DOI: 10.1016/j.actbio.2014.04.016
Charalambides, P.G., J. Lund, A.G. Evans and R.M. McMeeking, 1989. A test specimen for determining the fracture resistance of bimaterial interfaces. J. Applied Mechan., 56: 77-82. DOI: $10.1115 / 1.3176069$

Cotterell, B. and J.R. Rice, 1980. Slightly curved or kinked cracks. Int. J. Fracture, 16: 155-169. DOI: $10.1007 / \mathrm{BF} 00012619$

Fischer, J., P. Grohmann and B. Stawarczyk, 2008. Effect of zirconia surface treatments on the shear strength of zirconia/veneering ceramic composites. Dental Mater. J., 27: 448-454. PMID: 18717175

Gostemeyer, G., M. Jendras, L. Borchers, F.W. Bach and M. Stiesch et al., 2012. Effect of thermal expansion mismatch on the Y-TZP/veneer interfacial adhesion determined by strain energy release rate. J. Prosthodontic Res., 56: 93-101. DOI: $10.1016 /$ j.jpor.2011.09.002

Gostemeyer, G., M. Jendras, M.P. Dittmer, F.W. Bach and M. Stiesch et al., 2010. Influence of cooling rate on zirconia/veneer interfacial adhesion. Acta Biomaterialia, 6: 4532-4538. DOI: $10.1016 /$ j.actbio.2010.06.026

He, M.Y. and J.W. Hutchinson, 1989. Kinking of a crack out of an interface. J. Applied Mechan., 56: 270-278. DOI: $10.1115 / 1.3176078$

Kim, H.J., H.P. Lim, Y.J. Park and M.S. Vang, 2011. Effect of zirconia surface treatments on the shear bond strength of veneering ceramic. J. Prosthetic Dentistry. 105: 315-322. DOI: 10.1016/S0022-3913(11)60060-7

Kosyfaki, P. and M.V. Swain, 2014. Adhesion determination of dental porcelain to zirconia using the Schwickerath test: Strength Vs. fracture energy approach. Acta Biomaterialia, 10: 4861-4869. DOI: $10.1016 /$ j.actbio.2014.07.028

Kotousov, A., B. Kahler and M. Swain, 2011. Analysis of interfacial fracture in dental restorations. Dental Mater., 27: 1094-1101.

DOI: 10.1016/j.dental.2011.06.009

Mirsayar, M.M., 2013. Calculation of stress intensity factors for an interfacial notch of a bi-material joint using photoelasticity. Eng. Solid Mechan., 1: 149-153. DOI: 10.5267/j.esm.2013.09.006

Mirsayar, M.M., 2014a. On fracture of kinked interface cracks-the role of T-stress. Mater. Design, 61: 117-123. DOI: 10.1016/j.matdes.2014.04.074

Mirsayar, M.M., 2014b. A modified maximum tangential stress criterion for determination of the fracture toughness in bi-material notches-Part 1: Theory. Eng. Solid Mechan., 2: 277-282.

Mirsayar, M.M., 2014c. A new mixed mode fracture test specimen covering positive and negative values of T-stress. Eng. Solid Mechan., 2: 67-72. DOI: $10.5267 /$ j.esm.2014.2.006 
Mirsayar, M.M., 2015. Three dimensional investigation of mode $\mathrm{i}$ stress intensity factor variations in crack front using finite element method. Am. J. Eng. Applied Sci., 8: 11-16.

DOI: 10.3844 /ajeassp.2015.11.16

Mirsayar, M.M., M.R.M. Aliha and A.T. Samaei, 2014. On fracture initiation angle near bi-material notcheseffects of first non-singular stress term. Eng. Fracture Mechan., 119: 124-131.

DOI: 10.1016/j.engfracmech.2014.02.017

Mirsayar, M.M. and A.T. Samaei, 2013. Photoelastic study of bi-material notches: Effect of mismatch parameters. Eng. Solid Mechan., 1: 21-26. DOI: $10.5267 /$ j.esm.2013.06.001

Mirsayar, M.M. and A.T. Samaei, 2014. Application of maximum tangential stress criterion in determination of fracture initiation angles of silicon/glass anodic bonds. Eng. Solid Mechan., 2: 145-150.
Mosharraf, R., M. Rismanchian, O. Savabi and A.H. Ashtiani, 2011. Influence of surface modification techniques on shear bond strength between different zirconia cores and veneering ceramics. J. Adv. Prosthodont., 3: 221-228. DOI: $10.4047 /$ jap.2011.3.4.221

Wang, G., S. Zhang, C. Bian and H. Kong, 2014. Fracture mechanics analyses of ceramic/veneer interface under mixed-mode loading. J. Mechan. Behav. Biomed. Mater., 39: 119-128. DOI: 10.1016/j.jmbbm.2014.07.019

Yuuki, R. and J.Q. Xu, 1992. Stress based criterion for an interface crack kinking out of the interface in dissimilar materials. Eng. Fracture Mechan., 41: 635-644. DOI: 10.1016/0013-7944(92)90150-D 